\title{
Blut, Schweiß und Tränen
}

\section{Blood, Sweat and Tears}

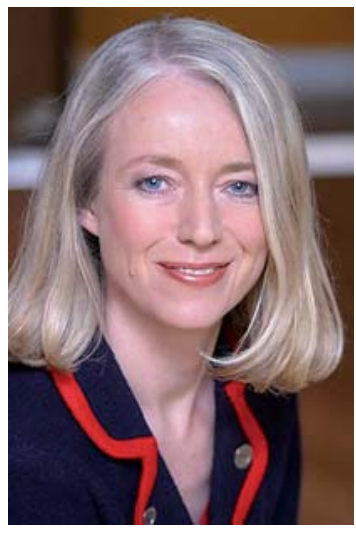

Prof. Dr. Christiane Bayerl
Es geht mir im Folgenden zunächst um den mittleren Begriff - Schweiß. Kaum ist es mal schön warm, setzt das große Gejammere über die unerträgliche Hitze ein. Das ist in der Tat ein Problem für unsere kranken Menschen auf Station, die nicht gewohnt sind 2-3 Liter pro Tag zu trinken. Da trinkt man besser weniger - dann schwitzt man auch nicht so. Es sitzt in den Köpfen fest, dass Schwitzen etwas Unfeines ist. In den vergangenen, klimatisch heißen Tagen habe ich an der Klinik die Parole herausgegeben, einigen älteren Patienten mit Infusionen zu helfen. Zum Kreislauf im wörtlichen und übertragenen Sinne schreibt Eugen Roth: „Das ist der Kreislauf dieser Welt: Mit saurem Schweiß verdient man Geld, mit süßem Leichtsinn wird's verlumpt das beste Herz uns nicht mehr pumpt.“

Die dreistufige Aufzählung des Titels der Churchill'schen Rede - auch hier im Titel - fokussiert aber nicht auf das Unästhetische des „sauren“ Schweißgeruchs, sondern auf Arbeit, Entbehrungen und Verzicht auf Luxus. Danach war der Terminus der „Blut, Schweiß- und Tränenrede“ geboren, wie wir ihn in der Politik immer wieder hören oder so mancher von seiner Geschäftsführung. Somit ist mit dem Schwitzen die Unvermeidlichkeit sich maximal anzustrengen und Opfer zu bringen assoziiert - auch etwas Schweißtreibendes.

Wir Ärzte verknüpfen Unerfreuliches mit dem Schwitzen, den Nachtschweiß bei B-Symptomatik oder die ganze Palette der dermatologischen Erkrankungen, nicht nur die Hyperhidrose, für die wir erfreulicherweise einen ganzen Strauß von therapeutischen Angeboten in der Hand halten, sondern auch die Bromhidrose und die Miliaria. Endlich hatten wir mal wieder einen Sommer, bei dem ich meinen Mitarbeitern eine Miliaria zeigen konnte! Weiter kennt unser Fach Erkrankungen, bei denen das Schwitzen ein begleitender Faktor zu den Korynebakterien ist, wie das Keratoma sulcatum oder die Trichomycosis palmellina.

Was die Medizingeschichte aber immer noch nicht genau benennen kann ist der Erreger, der hinter dem „englischen Schweiß“ steckt. Eher in den gehobenen Schichten und seit der Zeit Heinrichs VII. von England im VXI. Jahrhundert fielen die Seuchenwellen in England und dann in ganz Europa ein. Schottland und Irland blieben vollkommen verschont. Das Charakteristische dieser ansteckenden Infektionskrankheit mit tödlichem Ausgang waren die starken Schweißausbrüche. Die Mutmaßungen zur Ätiologie reichen von der Pest bis hin zu Grippe- oder Hantavirus-Infektionen. Die Symptomatik begann mit heftigem Schüttelfrost, Schwindel, Kopfschmerzen, Halsschmerzen und Gelenkbeschwerden, dem sogenannten kalten Stadium. Dem folgte ein urplötzlicher starker Schweißausbruch, Hitzegefühl, Delirium, rasender Puls, starker Durst und Nasenbluten. Jedoch wurde niemals ein Exanthem oder eine andere Veränderung an der Haut gesehen. Die Kranken verstarben nach 4-12 Stunden. Wer 24 Stunden überlebte, hatte eine Chance auf Heilung. Die zweite der sechs Gemahlinnen König Heinrichs des VIII., Anne Boleyn, soll am „englischen Schweiß“ gelitten haben. Die Seuche hat sie überlebt, ihren mörderischen Gatten nicht.

Schöne warme Sommertage!

Ihre

Prof. Dr. med. Christiane Bayerl

\author{
Bibliografie \\ DOI http://dx.doi.org/ \\ 10.1055/s-0030-1255694 \\ Akt Dermatol 2010; 36; 287 \\ (c) Georg Thieme Verlag KG . \\ Stuttgart · New York \\ ISSN 0340-2541
}

Korrespondenzadresse

Prof. Dr. med. Christiane BayerI

Klinik für Dermatologie und

Allergologie Wiesbaden

HSK, Wilhelm-Fresenius-Klinik

Städtisches Lehrkrankenhaus

der Universität Mainz

Aukammallee 39

65191 Wiesbaden

christiane.bayerl@

hsk-wiesbaden.de 